\title{
Epidemiology, Causative Agents and Clinical Features of Onychomycosis in El-Gharbia Governorate
}

\author{
M. Y. Bedaiwy, M. A. Metwally, N. A. El Zawawy and H. E. Saba\# \\ Department of Botany, Faculty of Science, Tanta University, Tanta, Egypt.
}

\begin{abstract}
O NYCHOMYCOSIS is a fungal disease of the nails that infects the nail plate, nail bed and matrix, caused by various species of dermatophytes, yeasts and molds. The aim of this investigation is to determine the clinicomycological and epidemiological profile of the etiologic agents of onychomycosis. The study population included 100 suspected cases of onychomycosis referred to the outpatient clinic at the Department of Dermatology at Tanta University Hospital, El-Gharbia Governorate, Egypt during 2015-2016. Nail clippings were collected in sterile Petri dishes for direct microscopic examination and culture. Fungal isolates were identified. The results showed that candidal onychomychosis was the most common clinical type. Candida tropicalis was the most prevalent causative species. It was more common among females aged $41-50$ years. The incidence was higher during summer and autumn seasons. Housewives were the commonest infected population. Fingernails were affected more frequently than toenails. The pattern of causative agents and clinical signs of onychomycosis is altering region to region, so repeated epidemiological surveys of onychomycosis seems to be fundamental. The present study provided novel and appropriate epidemiologic data of onychomycosis for the better prevention and treatment of this fungal infection.
\end{abstract}

Keywords: Onychomycosis, Dermatophytes, Candida, Epidemiology.

\section{Introduction}

Onychomycosis is a common fungal infection affecting both fingernails and toenails which usually caused by dermatophytes, yeasts and molds (Faergemann \& Baran, 2003). Onychomycosis occurs worldwide and accounts for upto $50 \%$ of all nail infections and $30 \%$ of all superficial fungal infections of the skin (Seebacher et al., 2008).

Onychomycosis is classified into five clinical types, according to the fungal invasion of the nail: Distal and/or lateral subungual onychomycosis (DLSO) which appeared when onycholysis, discoloration, subungual hyperkeratosis and thickening affecting the distal and/or lateral nail. White superficial onychomycosis (WSO) is white spots on or in the nail plate with textural changes. Proximal subungual onychomycosis (PSO), appeared if discoloration and onycholysis affected the proximal part of the nail. Candidal onychomycosis (CO) is characterized by markedly thickened and roughened nail plates. Total dystrophic onychomycosis (TDO) involves the entire nail bed and nail plate with thickening and roughening or destruction of nail plate (Rafiq, et al., 2013).
Dermatophytes are the main causative agent in temperate climates and account for $90 \%$ of toenail infections and at least $40 \%$ of fingernail infections (Singal \& Khanna, 2011). Trichophyton rubrum is the most common isolated dermatophyte followed by $T$. mentagrophytes and T. tonsurans (Seebacher et al., 2007 and Veer et al., 2007). Fingernail onychomycosis is more commonly associated with yeast infection, particularly Candida spp. (Meireles et al., 2008). The main nondermatophyte molds involved in onychomycosis are Scopulariopsis, Aspergillus, Fusarium, Penicillium and Scytalidium species (Narain \& Bajaj, 2016).

The prevalence of onychomycosis varies in different geographical areas due to several factors such as climate, socio-economical, occupational situations, aging, life-style and habits (Perea et al., 2000 and Sigurgeisson \& Steingrimsson, 2004).

In Egypt, higher priorities directed to other diseases, had resulted in low awareness of onychomycosis by physicians (El-Said, 2002). So, few data are available regarding the prevalence of onychomycosis. Therefore, this study was carried out to shed lights on the various clinical patterns, aetiologic agents and to correlate the clinical patterns with causative pathogens.

"Corresponding author email:habahebo1983@yahoo.com 


\section{Materials and Methods}

Study group

One hundred specimens were collected as nail clippings or nail debris from patients clinically diagnosed to have onychomycosis by specialists of dermatology. This was achieved by visiting the outpatient clinic of the Dermatology Department twice a week during a year from March 2015 to February 2016 at Tanta University Hospital, ElGharbia Governorate, Egypt. All patients provided an informed consent to participate in this study. The study was approved by the Ethics Committee of faculty of Medicine Tanta University.

The assessment of patients was conducted and consisted of an interview, clinical examination and collection of specimens for microbiological studies. All subjects completed a questionnaire that contained a demographic data, patient history, specific data related to risk factors for onychomycosis (age, gender and occupation) the clinical appearance according to site of lesion (DLSO, PSO, SWO, TDO and CO) and location of onychomycosis (toenail, fingernail).

\section{Specimen collection and processing}

The specimens were obtained from clinically affected nails, by a vigorous scrapping of the nail bed, the underside of the nail plate and the hyponychyum, after cleaning the affected area with $70 \%$ ethanol. Samples from each patient were placed in separate sterile Petri dish. All specimens were analyzed by direct microscopy and culture. Scales scraped from the nails were analyzed for fungal elements, such as hyphae or blastoconidia, by direct microscopy examination, in potassium hydroxide (20\%) (Rafiq et al., 2013).

\section{Culture and identification}

All nail samples were inoculated on each of two isolation media (1) Sabouraud dextrose agar with 5\% chloramphenicol (SDA, HiMedia laboratories) (2) SDA with 5\% chloramphenicol and cycloheximide in duplicate. Cultures were incubated at $25^{\circ} \mathrm{C}$ and $37^{\circ} \mathrm{C}$ and examined daily for six weeks. The identification of dermatophytes and non-dermatophyte moulds was performed by macroscopic and microscopic morphological examination of colonies as described by De Hoog et al. (2000) and Robert \& Pihet (2008). Yeasts isolates were identified by growth on Brilliance Candida agar (Oxoid Ltd., Hampshire, United Kingdom). Plates without growth, even after 4 weeks of incubation were considered negative. All the samples of dermatophytes were stained with Lactophenol cotton blue and then photographed.

\section{Statistical analysis}

Statistical analysis was carried out using a Pearson chi-square test to evaluate the significance of all the studied factors and the spread of onychomycosis.

\section{Results}

A total of 100 patients with suspected onychomycosis were enrolled during the present study period. Of these patients, $86(86 \%)$ were females and $14(14 \%)$ males as in Fig. 1. The prevalence of onychomycosis in different age groups showed that the patients ranging from 41 to 50 years $(40 \%)$ were the most commonly affected (Table 1). Table 2 and Fig. 2 showed the various clinical types and sites of nail involvement. The most common clinical type was candidal onychomycosis $(52 \%)$, followed by distal-lateral subungual onychomycosis (35\%), total dystrophic onychomycosis (11\%) and the least common was proximal subungual onychomycosis representing $(2 \%)$.

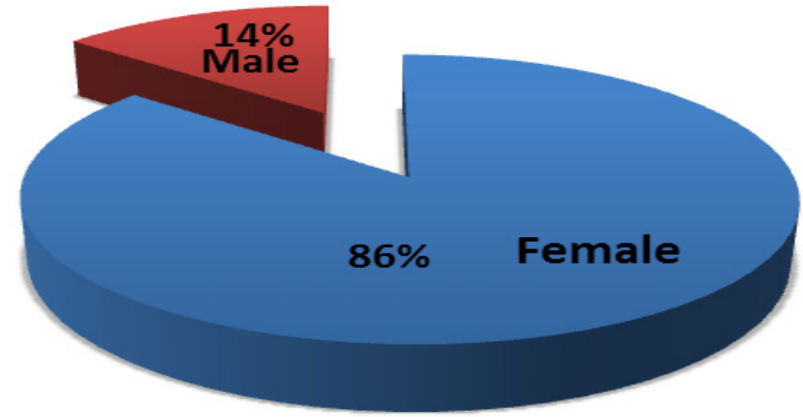

Fig.1. Percentage of onychomycosis among different sexes during the year of the survey (2015). 
TABLE 1. Distribution of onychomycosis among different sex and age groups.

\begin{tabular}{lccc}
\hline Age Group & \multicolumn{2}{c}{ Percentage of cases } & Percentage of total cases \\
\cline { 2 - 3 } & Female & Sex & \\
\hline & 2 & 0 & 2 \\
$\leq 10$ & 2 & 0 & 2 \\
$11-20$ & 8 & 0 & 8 \\
$21-30$ & 13 & 5 & 18 \\
$31-40$ & 34 & 6 & 40 \\
$41-50$ & 17 & 0 & 17 \\
$51-60$ & 10 & 3 & 13 \\
$>60$ & 86 & 14 & 100 \\
Percentage of total cases & & 8.482 & \\
Chi-square $\chi 2$ & & 0.205 & \\
p-value & & & \\
\hline
\end{tabular}

Statistical significant difference $(\mathrm{P}<0.05)$

TABLE 2. Classification of onychomycosis according to clinical types.

\begin{tabular}{lccc}
\hline \multirow{2}{*}{ Clinical type } & \multicolumn{2}{c}{ Nail site } & \multirow{2}{*}{ Total cases } \\
\cline { 2 - 3 } & Toenail & Fingernail & 52 \\
CO & 0 & 52 & 35 \\
DSO & 24 & 11 & 2 \\
PSO & 1 & 1 & 11 \\
TDO & 7 & 4 & 0 \\
WSO & 0 & 0 & 100 \\
Total & 32 & 68 & \\
Chi-square $\chi^{2}$ & & 51.340 & \\
p-value & & $0.00^{*}$ & \\
\hline
\end{tabular}

* Statistical highly significant difference $(\mathrm{P}<0.001)$

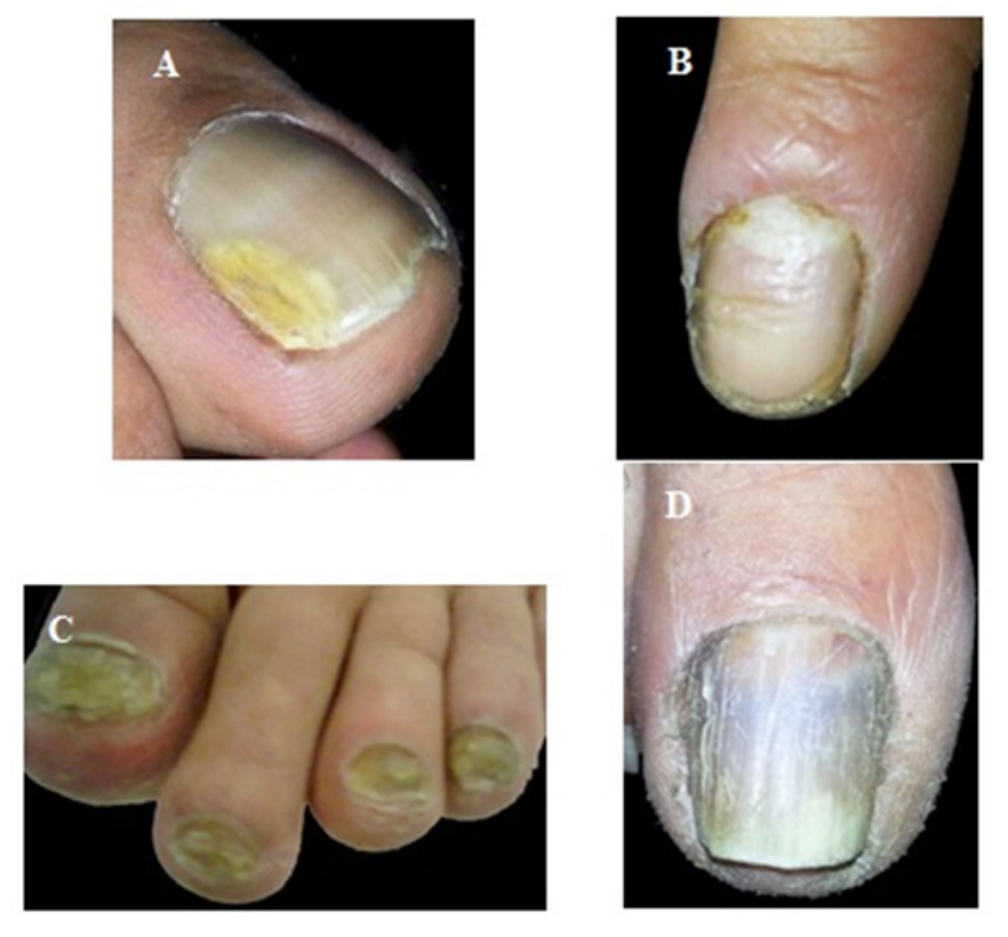

Fig.2. Different types of onychomycosis. (A) DLSO; (B) CO; (C) TDO; and (D) PSO. 
The data represented in Table 3 showed that onychomycosis was significantly more common among housewives ( 72 cases), followed by manual workers ( 16 cases) and farmers ( 7 cases), but less common among students (5 cases). The highest incidence of onychomycosis was observed in summer ( 43 cases), followed by autumn ( 25 cases). Spring ( 24 cases) and winter ( 8 cases) showed a low incidence of onychomycosis (Fig. 3).

TTABLE 3. Distribution of onychomycosis among different occupational careers during year of survey (2015).

\begin{tabular}{lc}
\hline Occupational career & No. of cases \\
\hline Housewives & 72 \\
Manual workers & 16 \\
Farmers & 7 \\
Student & 5 \\
Total & 100 \\
Chi-square $\chi^{2}$ & 120.560 \\
p-value & $0.00^{*}$ \\
\hline
\end{tabular}

${ }^{*}$ Statistical highly significant difference $(\mathrm{P}<0.001)$

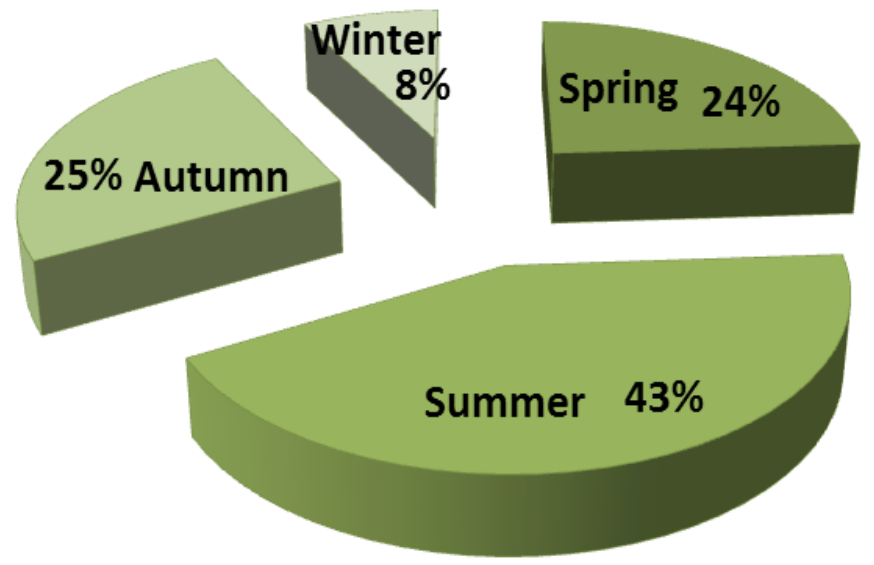

Fig. 3. Seasonal incidence of onychomycosis during the year of the survey (2015).

Fingernail onychomycosis was recognized in $68 \%$ of cases and toenail onychomycosis in $32 \%$. The rate of affected fingernails was higher in females in which yeasts were the most isolated agent (Table 4).

Fungal isolates causing onychomycosis in the present study were grouped into yeasts $(56 \%)$, dermatophytes $(36 \%)$ and non dermatophytes was detected in $8 \%$ (Fig. 4). This means that yeasts were the most common aetiological agent causing onychomycosis.

Table 5 showed that the most common yeast causing onychomycosis was Candida tropicalis
(20\%) followed by C. parapsilosis (10\%), C. glabrata (8\%), C.albicans (8\%) and C. krusei $(6 \%)$ and Rhodotorula species (5\%). Also, the most commonly isolated dermatophyte was Trichophyton mentagrophytes (17\%), followed by $T$. tonsurans (14\%) and T. verrucosum (5\%). Among the nondermatophyte moulds, Aspergillus niger (4\%), Aspergillus flavus and Chrysosporium $\mathrm{sp}$. were isolated from 2 patients.

Figure 5 represented the appearance of different Candida spp. on Brilliance Candida agar. Also Fig. 6 showed the macroscopic and microscopic appearance of dermatophytes and 
nondermatophytes causing onychomycosis. Culture of Trichophyton mentagrophytes (Fig. 6-1A) showed flat colonies with central folding, white to cream in color, and downy surface, with yellow-brown reverse pigment. Microscopic appearance (Fig. 6-1B) showed branched condiophores bearing numerous grape-like clusters of spherical microconidia. T. tonsurans (Fig. 6-2A) showed flat powdery yellow colonies, Fig. 6-2B showed balloon shape of microconidia. T. verrucosum (Fig. 6-3A) showed gray-white flat colonies, Fig. 6-3B showed globose microconidia produced on stalks. A. niger (Fig. 6-4A) showed colonies consist of dark-brown to black conidial heads, Fig. 6-4B showed large conidial heads, globose dark brown conidia. A. flavus (Fig. 6-5A) showed yellow to green color, flat granular colonies, Fig. 6-5B showed conidial heads are typically radiate, rough conidiophores covering the entire vesicle, and phialides point out in all directions. Conidia are globose to subglobose. Chrysosporium sp. (Fig. 6-6A) showed flat powdery orange color colonies which grow on cycloheximide, Fig. 6-6B conidia were typically pyriform to clavate with truncate bases.

TABLE 4. Distribution of fungal groups causing onychomycosis in various nail sites.

\begin{tabular}{|c|c|c|c|c|c|c|c|}
\hline \multirow{3}{*}{ Type } & \multicolumn{6}{|c|}{ No. of cases } & \multirow{3}{*}{ Total } \\
\hline & \multicolumn{3}{|c|}{ Fingernail } & \multicolumn{3}{|c|}{ Toenail } & \\
\hline & Male & Female & Total & Male & Female & Total & \\
\hline Dermatophytes & 5 & 7 & 12 & 6 & 18 & 24 & 36 \\
\hline Yeasts & 0 & 52 & 52 & 2 & 2 & 4 & 56 \\
\hline Filamentous fungi & 1 & 3 & 4 & 0 & 4 & 4 & 8 \\
\hline Total & 6 & 62 & 68 & 8 & 24 & 32 & 100 \\
\hline Chi-square $\chi^{2}$ & & 22.423 & & & 2.667 & & 13.269 \\
\hline p-value & & $0.00 *$ & & & 0.264 & & $0.001 *$ \\
\hline
\end{tabular}

${ }^{*}$ Statistical significant difference $(\mathrm{P}<0.05)$

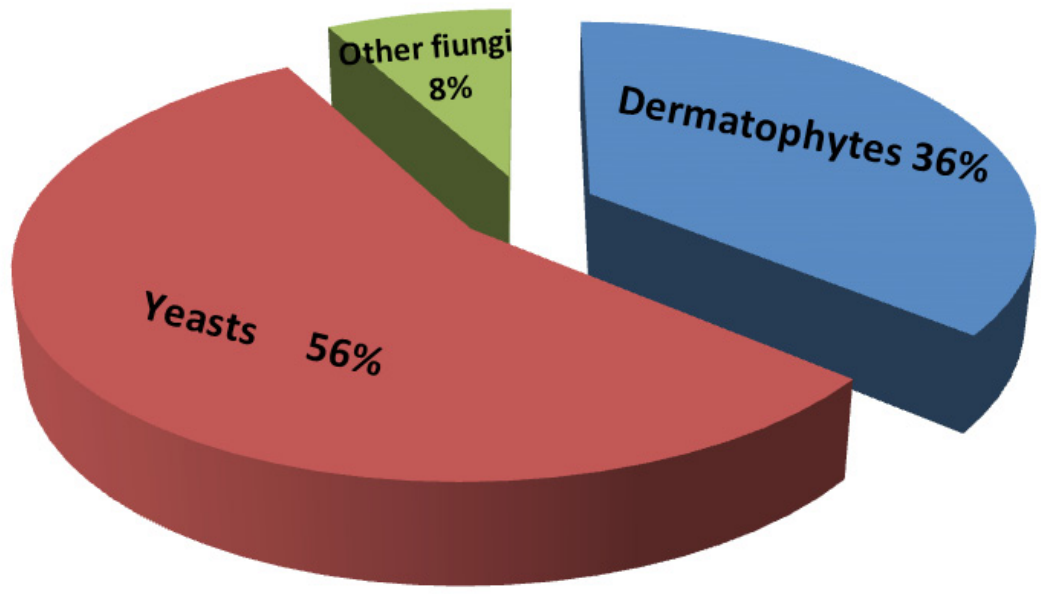

Fig.4. Causative agents of onychomycosis during the year of the survey (2015). 
TABLE 5. Fungal isolates causing onychomycosis during the year of study (2015).

\begin{tabular}{lc}
\hline Fungal isolates & Percentage of cases \\
\hline Yeasts: & 20 \\
C. tropicalis & 10 \\
C. parapsilosis & 8 \\
C. glabrata & 8 \\
C. albicans & 6 \\
C. krusei & 4 \\
Rhodotorula sp. & \\
Dermatophytes: & 17 \\
T. mentagrophytes & 14 \\
T. tonsurans & 5 \\
T. verrucosum & \\
Nondermatophytes: & 4 \\
Aspergillus niger & 2 \\
Aspergillus flavus & 2 \\
Chrysosporium sp. & 100 \\
\hline Total & \\
Chi- square $\chi^{2}$ & 45.68 \\
p-value & $0.00^{*}$ \\
\hline
\end{tabular}

* Statistical highly significant difference $(\mathrm{P}<0.001)$
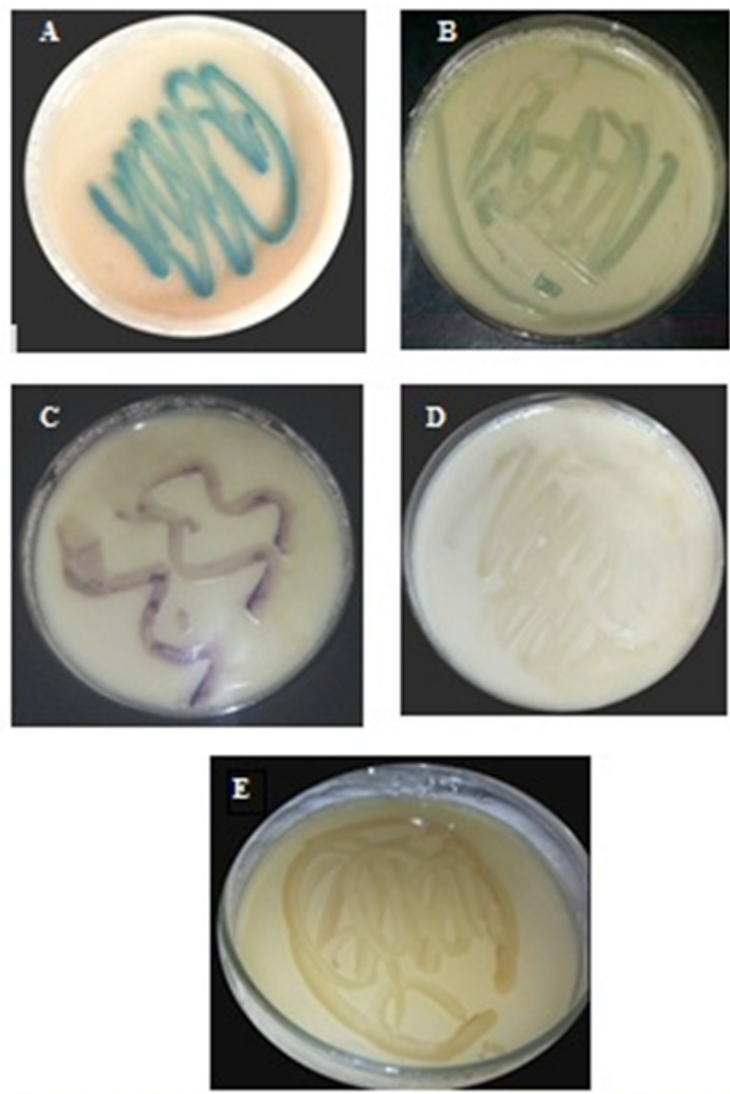

Fig.5. Phenotypic characteristic of Candida spp. on Brilliance Candida agar. 

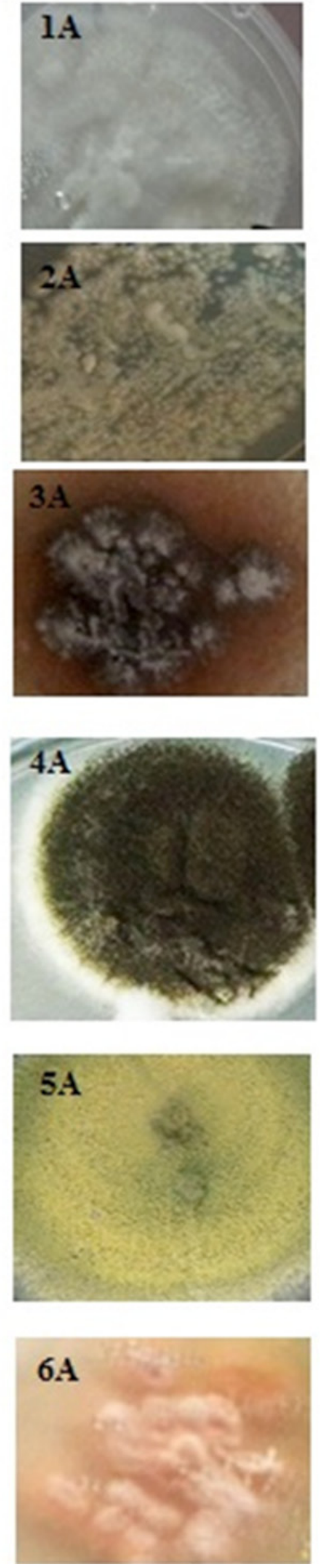
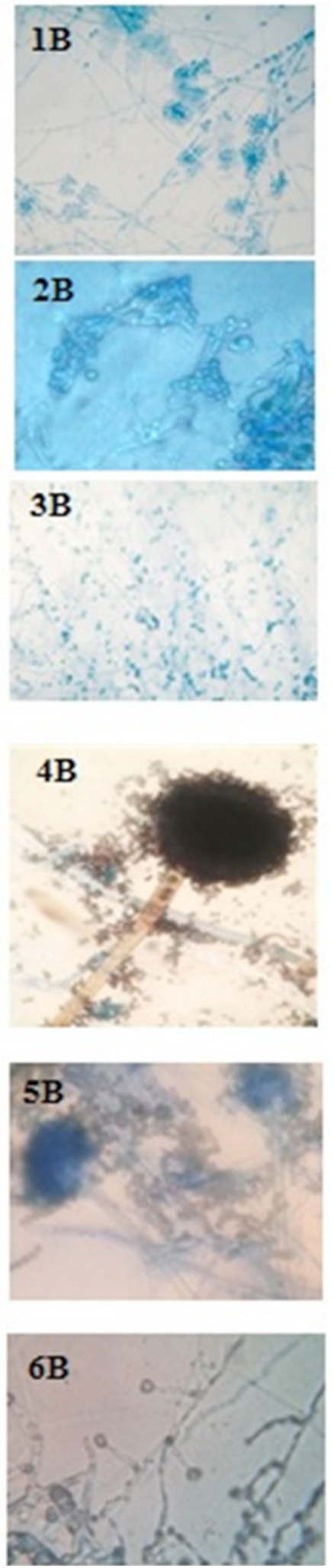

Fig. 6. Macroscopic and microscopic appearance of dermatophytes and nondermatophytes causing onychomycosis. (A)Culture and (B) microscopic appearance. (1) T. mentagrophytes; (2) T. tonsurans; (3) T. verrucosum; (4) Aspergillus niger; (5) Aspergillus flavus and (6) Chrysosporium sp. 


\section{Discussion}

Onychomycosis had been observed to be one of the most common nail diseases in patients applying to the outpatient department of dermatology at Tanta University Hospital, Tanta, Egypt. In the present survey, a total of 100 cases were recorded with onychomycosis over 12 months (March 2015February 2016).

In the present study, onychomycosis was found to be more common in females $(86 \%)$ than males (14\%). A similar female predominance $(62.9 \%)$ was reported by Afshar et al. (2014). This can be attributed to the fact that females do household wet work as laundry and house cleaning. On the other hand these results differ from some other studies which showed that onychomycosis was more common in males than females (Ahmad et al., 2010). In the present survey, onychomycosis affects all age groups. The most cases found in patients aged between 41 and 50 years. Similar observation was reported by Jayatilake et al. (2009) who observed that onychomycosis prevalence increases with age reaching its maximum 40-60 years old. On the contrary Grover (2003) reported a high prevalence in the age group of 20-40 years.

Housewives formed the largest group (72\%) in our study and this could be due to the involvement of housewives in domestic activities that include wet work like cleaning and laundry. They are also more concerned about cosmetic appearance of their nails. Similar results were reported by Chadeganipour et al. (2008) who found that housewives are the commonest. Other study carried out on 182 patients from 2006 to 2007 at Kathmandu, Nepal reported that housewives represent $28.5 \%$ of their patients (Neupane et al., 2009). This result was in contrast with Mudita et al. (2007).

In our study, fingernails were involved in $68 \%$ of patients while, toenails were involved in $32 \%$ of patients. These results were nearly similar to the results of a study in Indonesia (Bramono \& Budimulja, 2005), where fingernails were involved in $56.5 \%$ of patients and toenails in $17 \%$ of patients. On the other hand Mudita et al. (2007) found that toe nails were affected in $56.9 \%$, finger nails in $32.3 \%$ and both nails in $10.8 \%$ of patients. The low incidence of toenails onychomycosis in our country may be attributed to open footwear and less concern for appearance of feet and toe nails in our people.

The predominant clinical type of onychomycosis in our study was candidal onychomycosis $(52 \%)$ and was seen among patients whose occupations involved wet work followed by distal-lateral subungual onychomycosis (35\%) and the least common was total dystrophic onychomycosis (11\%). Reports from India showed that candidal onychomycosis $(58.82 \%)$ was the predominant clinical type followed by distal subungual onychomycosis (38.72\%) (Jesudanam et al., 2002).

In the present study the most frequently isolated fungal groups were yeasts $56 \%$ followed by dermatophytes in $(36 \%)$ and non-dermatophyte moulds (8\%). Higher isolation rate of Candida species $(52 \%)$ noted in this study came in harmony with those of Wajid et al. (2016) and Jesudanam et al. (2002). The most common isolated species in the present survey was Candida tropicalis (20\%). A similar result had been reported from Turkey (Manzano-Gayosso et al., 2011). On the other hand Abdo \& Abd Elrahem (2016) reported that dermatophytes were the most prevalent species (72.73\%) followed by non-dermatophytic molds. Trichophyton mentagrophytes was the most common dermatophyte isolated (17\%). Similar finding was reported from Iran (Aghamirinia \& Ghiasian, 2010). In India, Sarma et al. (2008) reported that $T$. rubrum was the most common dermatophyte associated with onychomycosis.

The frequency of fungal infections varies according to seasons. The highest frequency of onychomycosis $(43 \%)$ was in summer. Our results were similar to those reported by Ismael \& AlKafri (2016). This can be attributed to the fact that superficial mycoses grow best in warm and humid climate as in tropical and subtropical regions.

\section{Conclusion}

Itcanbeconcluded thatinEl-GharbiaGovernorate Egypt, the main cause of onychomycosis are yeasts followed by dermatophytes and a small number of cases are caused by filamentous fungi other than dermatophytes. Due to the long duration of therapy required for onychomycosis treatment regimen, it is important to increase awareness of people to protect themselves from infection. The results of our work don't differ significantly from those observed by previous researchers around the world, and any variation is probably due to the differences in climates and lifestyle conditions of the different study populations.

\section{References}

Abdo, H. and Abd Elrahem, S. (2016) Clinicomycological study of coexisting toenail onychomycosis and tinea 
pedis. Gulf J. Dermatol. Venereol. 23, 2.

Afshar, P., Khodavaisy, S., Kalhori, S., Ghasemi, M. and Razavyoon, T. (2014) Onychomycosis in north-East of Iran. Iran, J. Microbiol. 2, 98-103.

Aghamirinia, M.R. and Ghiasian, S.A. (2010) Onychomycosis in Iran; epidemiological and causative agent and clinical features. Jpn. J. Med. Mycol. 51, 23-29.

Ahmad, M., Gupta, S. and Gupte, S. (2010) A clinicomycological study of onychomycosis. Egyptian. Dermatol. Online J. 6, 4.

Bramono, K. and Budimulja, U. (2005) Epidemiology of onychomycosis in Indonesia : Data obtained from three individual studies. Jpn. J. Med. Mycol.46,171-176.

Chadeganipour, M., Nilipour, S. and Ahmadi, G. (2008) Study of onychomycosis in Ispahan, Iran. Mycosis. 52, 153-7.

De Hoog, G.S., Guarro, J., Gene, J. and Figueras, M.J. (2000) "Atlas of Clinical Fungi" (2 ${ }^{\text {nd }}$ ed). Centraalbureau voor Schimmelcultures, Utrecht, The Netherlands.

El-Said, A. (2002) Studies on Fungi Isolated from Dermatomycoses Patients in Egypt. Mycobiology, 30, 154-159.

Faergemann, J. and Baran, R. (2003) Epidemiology, clinical presentation and diagnosis of onychomycosis. British J. Dermatol. 149, 1-4.

Grover, S. (2003) Clinicomycological evaluation of onychomycosis at Bangalore and Jorhat. Indian J. Dermatol. Venereol. Leprol. 69, 284-286.

Ismail, M.T. and Al-Kafri, A. (2016) Epidemiological survey of dermatophytosis in Damascus, Syria, from 2008 to 2016. Curr. Med. Mycol. 2(3), 32-36.

Jayatilake, J.A., Tilakaratne, W.M. and Panagoda, G.J. (2009) Candidal onychomycosis: a mini-review. Mycopathologia, 168, 165-73.

Jesudanam, M.T., Rao, G.R., Lakshmi, D.J. and Kumari, G.R. (2002) Onychomycosis. A significant medical problem. Indian J. Dermatol. Venereol. Leprol. 68, 326-329.

Manzano-Gayosso, P., Mendez-Tovar, L.J., Arenas, R., Hernandez-Hernandez, F., Millan-Chiu, B. and Torres- Rodriguez, J.M. et al. (2011) Levaduras causantes de onicomicosis en cuatro centros dermatologicos mexicanos y se sensibilidad antifungica a compuestos azolicos. Onicomicosis por levaduras. Rav. Iberoam, Micol, 28: 32-5.

Meireles, T.E., Rocha, M.F., Brilhante, R.S., Cordeiro, A. and Sidrim, J.J. (2008) Successive mycological nail tests for onychomycosis: a strategy to improve diagnosis efficiency. Braz. J. Infect. Dis. 12(4), 3337.

Mudita, G., Nada, L.S., Anil, K.K., Vikram, K.M. and Gita, R.T. (2007) Onychomycosis:Clinico-mycologic study of 130 patient Hisamchal Pradesh, India. Indian J. Venereol. Lepro. 73, 389-392.

Narain, U. and Bajaj, A.K. (2016) Onychomycosis: Role of non dermatophytes. Int. J. Adv. Med. 3(3), 643-647.

Neupane, S., Pokhrel, D.B. and Pokhrel, B.M. (2009) Onychomycosis: A clinico-epidemiological study. Nepal Med. Coll. J. 11, 92-95.

Perea, S., Ramos, M.J., Garau, M., Gonzalez, A., Noriega, A.R. and del Palacio, A. (2000) Prevalence and risk factors of tinea unguium and tinea pedis in the general population in Spain. J. Clin. Microbiol. 38, 3226-3230.

Rafiq, A., Zakaria, A., Khondker, L., Khan, M.S.I., Doulah, S. and Hazra, S.C. (2013) Clinicomycological correlation in onychomycosis in a tertiary level hospital. J. Pakistan Assoc. Dermatol. 23, 277-283.

Robert, R. and Pihet, M. (2008) Conventional methods for the diagnosis of dermatophytosis. Mycopathologia, 166, 295-306.

Sarma, S., Capoor, M.R., Deb, M., Ramesh, V. and Aggarwal, P. (2008) Epidemiologic and clinicomycologic profile of onychomycosis from north India. Int. J. Dermatol. 47, 584-7.

Seebacher, C., Brasch, J., Abeck, D., Cornely, O., Effendy, I. and Ginter-Hanselmayer, G. et al. (2007) Onychomycosis. Mycoses, 50, 321-327.

Seebacher, C., Bouchara, J.P. and Mignon, B. (2008) Updates on the epidemiology of dermatophyte infections. Mycopathologia, 166, 335-352.

Sigurgeirsson, B. and Steingrímsson, Ó. (2004) Risk factors associated with onychomycosis. J. Eur. Acad. Dermatol. Venereol.18, 48-51.

Singal, A. and Khanna, D. (2011) Onychomycosis: diagnosis and management. Indian J. Dermatol. Venereol. Leprol, 77, 659-72.

Veer, P., Patwardhan, N.S., Damle, A.S. (2007) Study of onychomycosis : Prevailing fungi and pattern of infection. Indian J. Med. Microbiol. 25(1), 53-56.

Wajid, M.D., Khaleel, M.D. and Begum Amirunnisa, M.D. (2016) A Study of Onychomycosis in a Tertiary Care Hopsital in Hyderabad. Int. J. Contemporary Microbiol. 2(1), 13-16.

(Received 18/4/ 2017 ; acecpted $8 / 10 / 2017)$ 


\title{
الوبائية، العوامل المسببه والسمات السريريه للإلتهاب الفظرى للأظافر فى محافظة الغربية \\ محمد ياسر بايوي، متولى عبد العظيم متولى، نسمة أحمد الزواوى وهبة الله المرسى سبع

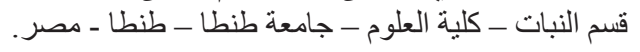

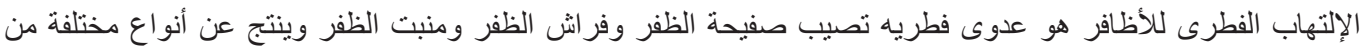

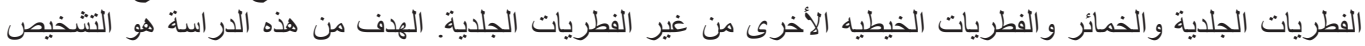

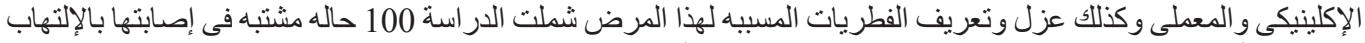

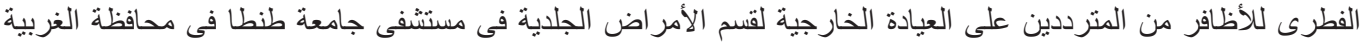

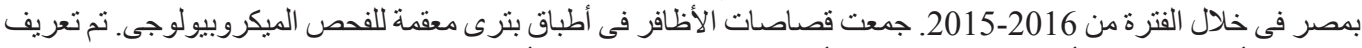

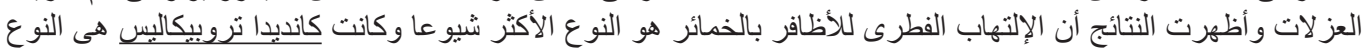

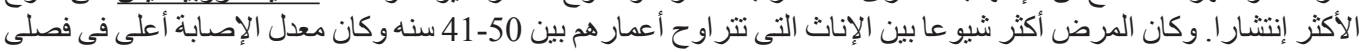

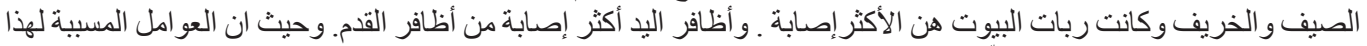

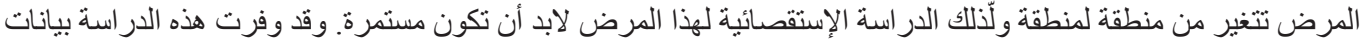
مناسبة للإلتهاب الفطرى للأظافر من أجل الوقاية من هذه العدوى الفطرية بشكل أفضل.
\end{abstract}

